\title{
Perceived Discrimination of Muslims in Health Care
}

\section{Mary Brigid Martin PhD, RN-BC, CTN-A}

Certified Transcultural Nurse

Nurse Educator

marybrigidmartin@gmail.com

I wish to acknowledge these scholars of Florida Atlantic University for their advisement in this research: Christine L. Williams, D.N.Sc., PMHCNS-BC, Marilyn Anne Ray, R.N., Ph.D., CTN-A, Robert Rabil, Ph.D., David Newman, Ph.D., and Joy Longo, Ph.D., R.N.

\section{Abstract}

Discrimination is not only a human and civil rights offense, but also a detrimental influence on the health outcomes of affected populations. The Muslim population in the United States is a growing religious minority increasingly encountered by health care professionals in the clinical setting. This group has been subject to heightened discrimination since the tragic events of September 11, 2001 and often is misunderstood within the context of American society today. While research has been conducted on discrimination against Muslims in the employment and educational segments of society, more studies are needed which quantify the extent and type of discrimination faced by this group in the health care setting. This inquiry focused on the crossover of anti-Muslim discrimination from society to the health care setting. A newly developed tool to measure anti-Muslim discrimination in health care and an established perceived discrimination scale were used to create the questionnaire employed in this investigation. The items of this newly created tool addressed culturally congruent care practices based on principles of cultural safety within the nurse-patient relationship and the cultural care beliefs of the Muslim patient/family to ascertain discriminatory occurrences in the health care setting. Ray's (2010) transcultural caring dynamics in nursing and health care model served as a framework for this quantitative, univariate, descriptive, cross- 
sectional design. Findings and implications for practice, policy, education, and recommendations for further research are discussed.

\section{Background and Rationale}

Discrimination is not only a human and civil rights offense, but also a detrimental influence on health and health outcomes. Populations that migrate often face discrimination and isolation and may compete with other groups for access to resources, including health care (Pacquiao, 2008). Minority groups, including immigrants and non-immigrants, exist in the United States in many forms including racial, ethnic origin, and religious affiliation. A growing religious minority of particular concern in the United States today is Muslims, who account for $0.8 \%$ of the overall U.S. adult population (Pew Research Center, 2011). While Muslim Americans have endured discrimination for decades prior to September 11, 2001, the tragedy of that day manifested a dramatic increase in anti-Muslim sentiment (Peek, 2011).

Notable national and international socio-political incidents have contributed to longstanding negative perceptions of Muslims, over the decades: ongoing conflict since Israeli statehood in 1948, the U.S./Iran hostage crisis and the U.S. Marine barracks attack in Beirut in the 1980s, World Trade Center bombing in the 1990s, and the landmark 9/11 attacks, when widespread fear and anti-Muslim sentiment greatly increased (Peek, 2011). Subsequently, Muslims have been subjected to exclusions, suspicion, verbal and physical attacks, and scrutiny about their culture, values, beliefs, and behaviors, which have been reinforced by negative media influences (Peek, 2011).

A lack of understanding about distinctions between Arabs and Muslims prevailed; all Arabs are not Muslim and all Muslims are not Arabs. Muslims are followers of the religion Islam, and may be found all over the world; Arabs are a heterogeneous ethnic group from 22 Arabic-speaking nations across the Middle East and northern Africa which comprises Christians, Muslims, and other religions (Peek, 2011). A recent report published by the Arab American Institute (2014) reveals declining favor in American attitudes towards Arab Americans and Muslim Americans which puts their inclusion and civil rights at risk; polls take in 2010 and 2014 for Muslim Americans for favorable rating dropped from $36 \%$ to $27 \%$, and for Arab Americans, dropped from $43 \%$ to $32 \%$, respectively.

Followers of Islam are misunderstood, misinterpreted, and often feared due in part to prevailing derogatory media influences prior to and since $9 / 11$ (Smith, 2009). While discriminatory actions inflicted upon Muslims have been reported in employment (Carlsson \& Rooth, 2007; Fozdar, 2011; Ghumman \& Jackson, 2010; Ghumman \& Ryan, 2013; King \& Ahmad, 2010; Scott \& Fran- 
zmann, 2007; Widner \& Chicoine, 2011) and education settings (Aroian, 2012; Shammas, 2009), there is insufficient information available to ascertain the occurrence of anti-Muslim discrimination in the health care setting.

\section{Purpose}

The purpose of this research was to ascertain the extent of perceived antiMuslim discrimination in the United States, the extent of perceived anti-Muslim discrimination in U.S. health care settings, and the types of discriminatory behaviors Muslims report in the American health care setting. Additionally, the researcher aimed to uncover care preferences among Muslim Americans that may inform culturally congruent care practices, and to test the reliability and validity of a newly developed instrument designed to measure anti-Muslim discrimination in the health care setting.

\section{The Muslim American Population}

Muslims are a growing religious minority in the United States today. While statistics vary, the Muslim population is speculated to be between 2 and 7 million; since the U.S. Census does not track religion, data are estimated: 34\% Pakistani or South Asian, 26\% Arab, and 25\% African American (U.S. Department of State, 2009). The number of mosques in the country has risen dramatically: in 1939, there were 19 (Bagby, Perl, \& Froehle, 2001); in 2011 there were 2,106, including a 74\% increase from 2000 when 1,209 mosques were counted (Bagby, 2011).

Of the majority, 65\% are foreign born, 35\% are U.S. born, and approximately 20\% are African Americans (Pew Forum on Religious and Public Life, 2008). Of the foreign born, $25 \%$ are Arab immigrants from the Middle East; the rest include immigrants from South Asia (including Pakistan, India, and Bangladesh), Turkey, Iran, Malaysia, Indonesia, Nigeria, Somalia, Liberia, Kenya, and Senegal (U.S. Department of State, 2009). Languages spoken reflect countries of origin and include English, Arabic, Urdu, Farsi, Turkish, Indonesian, and African languages; non-Arab Muslims must know a minimum amount of Arabic, as prayer requires recitation of Qur'an in Arabic, in the original revelation language of Islam (Nigosian, 2004). Muslim Americans dwell mainly in the states of California, New York, Illinois, New Jersey, Indiana, Michigan, Virginia, Texas, Ohio, and Maryland, and in the cities of New York, Los Angeles, Chicago, and Detroit/Dearborn (U.S. Department of State, 2009). Most are highly educated, fluent in English, politically astute, and hold a similar economic status to the main population; the majority are employed, one-fourth 
hold bachelor degrees, and one-fourth live in households with annual incomes of $\$ 75,000$ or more (Read, 2008). This population growth increases the likelihood of American health care professionals encountering Muslim patients with specific culturally influenced health care needs (Padela, Gunter, Killawi, \& Heisler, 2012).

\section{Problem Statement}

The problem of anti-Muslim discrimination crossover to the health care setting is a subject which, if not addressed, has detrimental outcomes, including 1) health disparities, 2) adverse mental health impact, and 3) health care provider lack of knowledge about culturally congruent care. Anti-Muslim discrimination leads to disparity in health care by negatively impacting the health and care of Muslim families (Laird, Amer, Barnett, \& Barnes, 2007).

There is growing concern about the impact of anti-Muslim discrimination on mental health (Ahmed \& Reddy, 2007). Investigations about Arab Americans and Muslim Americans cite an array of problems including depression, post-traumatic stress disorder, psychological distress and stress, and poor selfesteem (Abu-Ras \& Abu-Bader, 2009; Ahmed \& Reddy, 2007; Amer \& Hovey, 2007, 2012; Barkdull et al., 2011; Erickson \& Al-Tamimi, 2001; Ghaffari \& Çiftçi, 2012; Hassouneh \& Kulwicki, 2007; Jasperse, Ward, \& Jose, 2012; Kira et al., 2010; Moradi \& Hasan, 2004; Padela \& Heisler, 2010; Rippy \& Newman, 2006, 2008). Charles and Daroszewski (2010) affirmed the need for providers to comprehend Islamic cultural perspectives in order to provide culturally competent care to this population. Historic and present social contexts, prejudice, and bias may also influence discriminatory behaviors among providers (Ray, 2010; Smedley, Stith, \& Nelson, 2002). Muslim Americans are an underserved, understudied minority of ethnic and racial diversity that may pose challenges for health care providers unfamiliar with Islamic health influences; Muslim patients may have expectations in the health care setting that, if not met, may generate feelings of discrimination or poor clinical experiences (Padela, Gunter, Killawi, \& Heisler, 2012).

\section{Theoretical Framework}

Ray's (2010) Transcultural Caring Dynamics in Nursing and Health Care model (see Figure 1) served as a research framework because of its emphasis on the relatedness of human-environment connection, particularly with respect to sociocultural and socio-political context within which Muslim Americans dwell since 9/11. Ray (2010) attested that contextual dynamics within one's societal environment have crucial influences on worldview and wellbeing. While many 
Figure 1. Ray's transcultural caring dynamics in nursing and health care model. From Ray, M. (2010). Transcultural caring dynamics in nursing and health care $\left(1^{\text {st }}\right.$ ed.). Philadelphia, PA: F.A. Davis Company, with permission.

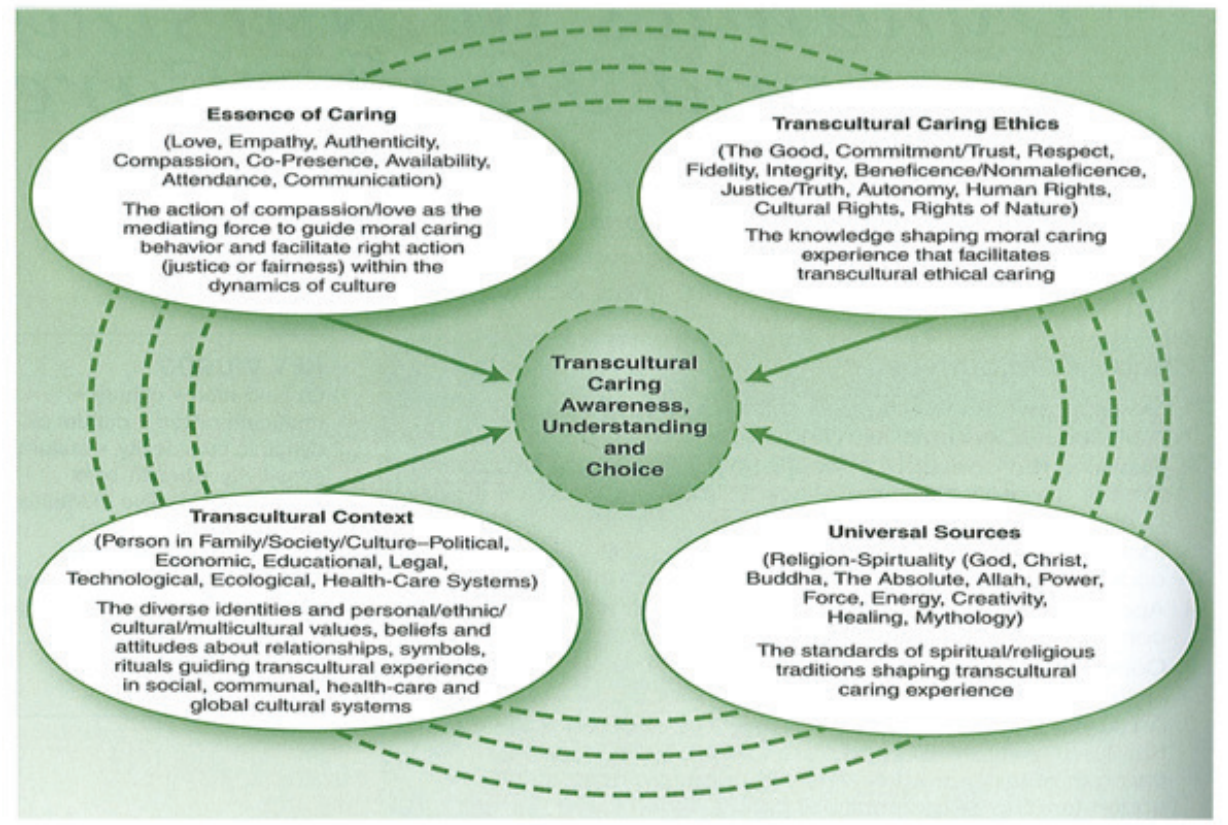

transcultural nursing constructs are available, Ray's (2010) model was selected as a conceptual guide for this investigation due to distinct emphases that set it apart from other theories: (a) the interrelational nature of the provider-patient relationship; (b) the complex, relational, dynamic nature of cultural influences on spirituality, ethics, context, and how caring is expressed; and (c) how these forces relate to awareness, understanding, and choice within the providerpatient relationship. This model is intended for interdisciplinary use; the translational nature of this work is such that it "applies to professionals and patients in a reciprocal relationship and engaged in choice making regarding caring, health, illness, death, healing, and wellbeing" (p. 20). The dynamic nature of the framework aligns with the global changes and challenges within health care professionals currently practice, and thus supports the imperative to seek knowledge about meaningful care for Muslim Americans today.

\section{Application of the Model to American Muslims}

The four aspects of Ray's (2010) model, essence of caring, transcultural caring ethics, transcultural context, and universal sources, are relationally associated with its central theme of transcultural caring awareness, understanding, and 
choice. The following describes how this framework applies to Muslim American and Islam.

Transcultural caring in Islam. Caring is an expression of love and mutual concern expressed within cultural contexts. The concept of caring among Muslims is "embedded in the theological framework of Islam" (Rassoul, 2000, p. 1481). For Muslims, illness may be seen as a time to reflect upon one's faith and spiritual growth during illness and recovery (Rassoul, 2000). Caring for family in times of health and illness is a moral and religious obligation in Islam (Wehbe-Alamah, 2008). In Islam, social ties give meaning and purpose in life and are central to leisure and recreation. Muslims show they care about each other by frequent contact, conversation, social gatherings, and shared rituals. Health care workers will notice the presence of family as a source of security and support in times of sickness. During illness and death, visitation is expected, a much respected obligation that conveys the significance of being available and attentive to family needs.

Transcultural ethics-Islamic ethics and patient care. Ray (2010) explained that transcultural caring ethics considers ethical understanding, which recognizes Western and other cultural ethical principles, and acknowledges ethical relativism and universalism. Islamic ethics are steeped in its faith and include acceptance of the will of God; however, there is respect and acknowledgement of active ethical health promotion. Rassoul (2000) adapted an Islamic code of ethics from the work of Athar (1996), which detailed priorities of the ethicist in patient care: involvement of the family and patient in decisionmaking, interpretation of the Qur'an as related to patient concerns, consolation of patient and family to pray for acceptance of God's will regarding health status, and attention to the needs of the family after death has taken place. These concerns uphold the role of health care providers to support family involvement in care; to value spirituality as a means of comfort, hope for wellness, recovery from illness, and peaceful death; and to promote family support after peaceful end of life.

The four universal ethical principles of respect for autonomy, beneficence, non-maleficence, and justice may assist health care providers in analyzing ethical dilemmas, but require cultural considerations of all patients including Muslims (Westra, Willems, \& Smit, 2009). The concepts of autonomy and nonmaleficence must be considered by the non-Muslim provider in that within the Islamic faith, life and death are decided by God. For example, decisions such as withdrawing life-sustaining treatment of a Muslim patient and family may be debatable, as may also be the case with non-Muslim patients and families.

A discussion of ethics and Islam includes well-debated and controversial issues faced by patients and health professionals today, regardless of faith. Broadly speaking in Islam, reversible contraception and in-vitro fertilization (using only husband and wife as sources) are acceptable, as is abortion, but only 
for medical reasons; permanent sterilization and embryonic experimentation are unacceptable; and Muslim babies who die in utero and are more than 120 days old should be named and buried (Charles \& Daroszewski, 2012). Assisted suicide, euthanasia, and cloning are unacceptable, and prolonged life support is discouraged; however, genetic engineering to cure disease, blood transfusion, organ transplantation, and the use of a living will are acceptable practices (Rassoul, 2000). Some Muslim families may reject informing loved ones of their diagnosis and/or prognosis as a means of protection from emotional distress; however, there is no Islamic basis for this behavior.

While the principles of Islam are unchanging, in health care the science upon which judgments are made may change over time, and practitioners must realize that differing views in bioethical matters do exist among Muslims (Kyriakides-Yeldham, 2005). Respect for individual choice among a population as diverse as Muslims must be taken into account by providers. Recognition of the commonalties and complexities of ethical values among Muslim patients and health care providers will advance ethical understanding as related, connected, and universal.

Transcultural context and socio-political context of Muslim Americans. Longstanding suspicion of Muslims has been instigated by decades of events worldwide in which Muslims are central, and contribute to ongoing discrimination faced by this group today (Ahmed \& Reddy, 2007). The sociopolitical context in the United States, including and preceding September 11, 2001, has impacted life for Muslims in the United States. Muslim Americans have encountered discrimination more than any other religious group in this country since September 11, 2001 (Pew Forum on Religious and Public Life, 2009). Muscati (2002) described a sense of "otherness" (p. 131) that emerged about Muslims since the Gulf War and the Iraq crisis in which Muslims were dehumanized universally and perceived of as a threat. Lingering resentment toward Muslims persists (Pew Forum on Religious and Public Life, 2009). The prejudice and exclusion that Muslim Americans encountered before and after 2001 were worsened by a range of discriminatory behaviors endured, such as verbal and physical assaults and hate crimes (Peek, 2011).

While Muslims face challenges related to discrimination in the United States, this group values the social principles of this country. Huda (2006) explained that Muslim Americans do not view any conflict between democracy and Islam; Islamic organizations call for greater community involvement, education, and self-scrutiny of their larger heritage to advance combining religious values with the American experience in order to promote mutual understanding.

Universal Sources-Muslims and Islam. Knowledge of how religious belief systems interface with illness and care is essential in a pluralistic health care system where providers and patients have diverse religious views (Koe- 
nig, 2005). Application of Ray's (2010) construct to direct an understanding of Muslim Americans must include an appreciation for the principles of Islam and their meaning to its followers. Islam offers its believers not only a theology, but also a way of life, a united worldview, belief in salvation, an afterlife, the meaning of acceptable deeds, and specific tenets to adhere to in life. Teachings of Islam are based on the original and unchanging Quranic text that was relayed thorough the angel Gabriel in Arabic to prophet Mohammed, and hadiths, or teachings of the prophet (Iqbal, 2007). Nasr (2003) explained that the Muslim soul is connected to Qur'anic expressions such as Insha'Allah (if God wills), alhumdu li'Llah (thanks be to God), and bismi'Llah (in the name of God).

Islam and science have been related since Islam's inception as a world religion, which caused a social and intellectual revolution that transformed society (Iqbal, 2007). The Qur'an, the Muslim holy book, offers the groundwork for the philosophies of Islamic civilization and the relationships between this faith and science, nature, and human life (Iqbal, 2007). To belong to Islam is to be part of a community of Muslim brothers and sisters who share deep connections to this faith. An example of this powerful relatedness is that Islamic prayer and fasting rituals are grounded in the same principle of the sunrise and sunset, thus creating a sense of unity. This principle of connectedness in Ray's (2010) model applies to this sense of unison in Islam and enlightens understanding of the value of spiritual unity among Muslims.

Understanding, awareness, and choice for Muslims. The central connecting core of Ray's (2010) construct integrates caring, ethics, context, and spirituality into the need for awareness, understanding, and choice in the care of the Muslim population in the United States. An appreciation for the Islamic religion, its values, beliefs, and customs is imperative to create mutual understanding and a sense of community among Muslims and non-Muslims in the United States. This approach also has health care benefits; when a patient's cultural needs are met, it is more probable that they will follow a plan of care than if cultural needs are not met (Maier-Lorenz, 2008). Gaining knowledge about Islam, not only as a religion, but also as a way of life, will assist health care providers to grasp the impact of this faith on the health and wellness of the Muslim patient and family. Subsequently, the attainment of successful care collaboration and treatment plans may reinforce behaviors endorsed by Islam and promote patient satisfaction. Wehbe-Alamah (2008), a Muslim nurse scholar, explained that care provisions may include dietary considerations; respect for modesty; access to same-sex caregivers, if requested; support for prayer rituals; and promotion of social support for the ill.

The Muslim diet prohibits pork and alcohol (Wehbe-Alamah, 2008); otherwise, diets vary among Muslim Americans and may reflect the ethnic backgrounds of this group, including, but not limited to, Arab, Persian, Pakistani, Asian, African, European, and African Americans. It is optimal for pious Mus- 
lims to eat meat that is halal: slaughtered according to Islamic tradition, with a prayer recitation noting the animal is a blessing from God, after which the neck vessels are cut and blood is drained (Riaz \& Chaudry, 2003). The use of the hijab or a head scarf and clothing that is not revealing are ways to observe the modesty of women valued in Islam (Nasr, 2003). Conservative Muslims may prefer same-sex caregivers in keeping with respect for gender boundaries (Wehbe-Alamah, 2008). The performance of daily prayer rituals at five set times each day is a tenet of Islam that devout Muslims observe (Nasr, 2003), and these rituals likely will be performed while the patient is in the health care setting. Immediate and extended family support may be evidenced by frequent visitation to the patient, even a desire to stay with the patient while hospitalized (Wehbe-Alamah, 2008). Health care providers who attempt to accommodate and advocate for Muslims to have choice in their care convey appreciation and respect for Islamic values and support patient satisfaction. This study aims to uncover preferences for culturally appropriate care accommodations as described by Muslim Americans.

\section{Research Design}

For this quantitative, univariate, descriptive, cross-sectional inquiry, a 33-item established perceived discrimination scale which measures anti-Muslim discrimination in society, the Perceived Religious Discrimination Scale (PRDS; Rippy \& Newman, 2008), was employed. The range of possible scores for this scale is 0 to 132; higher scores indicated stronger confirmation of exposure to negative religious discriminatory experiences (Rippy \& Newman, 2008).

The researcher created a new 15-item tool, the Health Care Discrimination Scale (HCDS), which comprises two subscales of six items each, and three questions. The first six items became the health care cultural safety subscale (HCCS), and addressed cultural safety (Ramsden, 1996), evident in the provider-patient relationship: patient perception of fair treatment, culturally competent care, choice, respect for identity, safety and security, and knowledge of culture (Polascheck, 1998). The remaining six items addressed patient/family cultural needs representative of Muslim care beliefs including prayer rituals, family involvement, privacy, diet, same-sex caregiver preference, and modesty, as affirmed by Wehbe-Alamah (2008). One close-ended dichotomous item, one checklist style open-ended item, and one rank order open-ended item addressed self-reported discrimination in the health care setting, the types of discrimination faced, and care preferences, respectively. An "Other" option in one of these questions elicited free text responses. The range of possible scores for the HCDS total was 0 to 48; higher scores indicated stronger confirmation of exposure to discriminatory experiences, The electronic questionnaire, com- 
prised of Likert scale and open-ended questions, was created using a private, password-protected Survey Monkey account in the researcher's name.

\section{Sample, Setting, Consent, Benefits and Risks, Data Analysis}

A nationwide convenience sample of 227 adults (over 18 years) who reside in the United States, report Islam as their religion, either by birth or conversion, and had a health care encounter since 9/11, participated in this investigation between January and April 2012. Participants were accessed by email, Facebook, and snowball sampling. A 14-item questionnaire elicited sociodemographic data. Additional information related to religiosity was included: mosque attendance and use of clothing that identifies one as Muslim. Participants were provided information about the study; completion of surveys served as consent.

The only benefit to the participants was the knowledge they contributed to the research that may inform health care providers about the needs of this cultural group. Risks involved included emotional stress when asked about discrimination; its remedy was to skip any questions or discontinue participation in the survey. All participant responses were anonymous and kept confidential. SPSS Version 21.0 was used to analyze the data.

\section{Findings Related to Research Questions}

Demographic characteristics of the sample were consistent with the national education, employment, and income demographics of Muslim Americans (Read, 2008; see Table 1).

RQ1. What is the estimated reliability and validity of the newly developed HCDS?

Reliability. Two types of reliability were addressed for the HCDS: internal consistency and stability. Internal consistency of the HCDS was estimated using Cronbach's alpha. Both the overall measure and its subscales were assessed as well as inter-item correlations. Nunnally (1978) explained that acceptable internal consistency for a new instrument is .70 - .79, whereas a value in the range of .80 to .89 may be considered moderate, and a range of .90 to .99 is considered excellent. Reliability measures of the HCDS incorporated examining the two subscales therein, and HCPF, individually as well as summed (HCDS). The HCDS was found to have acceptable reliability for a new instrument $(N=218$, 12 items; $\alpha=.78)$. The subscale HCCS was found to have moderate reliability 
TABLE 1. Sociodemographic Characteristics of Sample

\begin{tabular}{|c|c|c|c|c|}
\hline Sociodemographic & M & $S D$ & $f$ & $\%$ \\
\hline \multicolumn{5}{|l|}{ Gender $(N=189)$} \\
\hline Male & & & 74 & 39.2 \\
\hline Female & & & 115 & 60.8 \\
\hline Age $(N=191)$ & 38.23 & 13.45 & & \\
\hline Years of Education $(N=191)$ & 16.94 & 2.74 & & \\
\hline \multicolumn{5}{|l|}{ Marital Status $(N=189)$} \\
\hline Single/Never married & & & 47 & 24.8 \\
\hline Married/Living with partner & & & 131 & 69.3 \\
\hline Divorced/Separated & & & 11 & 5.8 \\
\hline \multicolumn{5}{|l|}{ Employment Status $(N=190)$} \\
\hline Employed & & & 129 & 67.9 \\
\hline Unemployed & & & 54 & 28.4 \\
\hline Retired & & & 7 & 3.7 \\
\hline \multicolumn{5}{|l|}{ Ethnicity $(N=171)$} \\
\hline Arab & & & 60 & 30.8 \\
\hline Pakistani & & & 28 & 14.4 \\
\hline African & & & 6 & 3.1 \\
\hline Asian & & & 11 & 5.6 \\
\hline European/E.European & & & 25 & 12.8 \\
\hline Hispanic/Latino & & & 5 & 2.5 \\
\hline Indian & & & 21 & 10.8 \\
\hline Persian & & & 4 & 2.0 \\
\hline African American & & & 11 & 6.4 \\
\hline Sociodemographic & $M$ & $S D$ & $f$ & $\%$ \\
\hline \multicolumn{5}{|l|}{ Other Ethnicity $(N=24)$} \\
\hline Afghani & & & 1 & .5 \\
\hline Algerian/Berber & & & 3 & 1.5 \\
\hline American & & & 8 & 4.2 \\
\hline Mixed Ethnicity & & & 4 & 2.0 \\
\hline Guyanese & & & 1 & .5 \\
\hline Indo/Pakistani & & & 1 & .5 \\
\hline Native American & & & 1 & .5 \\
\hline North African & & & 1 & .5 \\
\hline White & & & 4 & 2.1 \\
\hline \multicolumn{5}{|l|}{ Born in the U.S. $(N=191)$} \\
\hline Yes & & & 85 & 44.5 \\
\hline No & & & 106 & 55.5 \\
\hline \multicolumn{5}{|l|}{ Muslim Clothing $(N=190)$} \\
\hline Yes & & & 119 & 62.6 \\
\hline No & & & 71 & 37.4 \\
\hline
\end{tabular}




$\begin{array}{lrr}\text { Income }(N=189) & & \\ \text { Less than } \$ 10,000 & 9 & 4.8 \\ \$ 10,000-\$ 50,000 & 43 & 22.8 \\ \$ 50,000-\$ 100,000 & 43 & 22.8 \\ \$ 100,000-150,000 & 34 & 18.0 \\ \$ 150,000-\$ 200,000 & 19 & 10.1 \\ \text { Greater than } \$ 250,000 & 12 & 6.3 \\ \text { Prefer not to respond } & 29 & 15.3\end{array}$

Note. $M=$ mean, $S D=$ standard deviation.

$(N=222,6$ items; $\alpha=.87)$. Cronbach's alpha scores for the subscale HCPF fell slightly below acceptable reliability $(N=221,6$ items; $\alpha=.66)$.

The HCDS, HCCS, and HCPF were evaluated for inter-item correlation and degrees of correlation from low to moderate according to Tappen (2011). The results of this analysis revealed that items of the HCCS were moderately correlated $(r=.53, p=.05)$, the items of the HCPF were low to moderately correlated $(r=.24, p=.05)$, and the items of the HCDS were moderately correlated $(r=.33, p=.05)$. Deletion of any item makes no substantive change nor will improve the reliability of the scale.

Stability. A test-retest approach was utilized to address stability of the HCDS. To do this the HCDS was administrated to the same individuals on two occasions under the same conditions. The investigator sent the HCDS by email to 10 volunteers who met inclusion criteria and who agreed to complete the tool on two separate occasions, approximately two weeks apart. This procedure yielded two scores for each person, which then were compared. These two sets of scores created the test-retest reliability coefficient. The mean scores for the test and retest scores were 13.30 and 12.20 , respectively. The standard deviation for the test and retest scores was 9.09 and 9.50, respectively. The test-retest coefficient was determined using Pearson Product Moment Correlation $r=.98$, which indicated a very high estimate of stability.

Content validity. To determine whether items were appropriate indicators of perceived discrimination in health care, five researchers with expertise on the Muslim population were asked to complete a 4-point Content Validity Index (CVI) scale, ranging from $1=$ not relevant to $4=$ very relevant. Eight of the 15 items were deemed valid for the HCDS, which resulted in a summary CVI score of .53, below the acceptable level of .90. This indicated a need to revise the HCDS; this was not done in this study.

Concurrent validity. To discern concurrent validity of the HCDS and the PRDS, a correlation matrix was employed. Results indicated that the PRDS was significantly correlated with the HCDS $(r=.59, p=.01)$, the HCPF $(r=.33, p=$ $.01)$, and $\operatorname{HCCS}(r=.52, p=.01)$.

To address the question, "Did you ever feel that you were discriminated 
against in the health care setting because you are Muslim?" (Question \#13), the researcher used a $t$-test to compare the dichotomous "Yes/No" responses to each of the measures (HCDS, HCCS, HCPF, and PRDS); this was done to ascertain comparisons between anti-Muslim discrimination in the United States and anti-Muslim discrimination in the U.S. health care setting. This approach supported the estimation of concurrent validity of the HCDS. All relationships were found to be significant (see Table 2).

TABLE 2. Comparisons Between Anti-Muslim Discrimination in the United States and AntiMuslim Discrimination in the U.S. Health Care Setting Using Independent $t$-test

\begin{tabular}{lccrcrrrrrc}
\hline \multicolumn{10}{c}{ Question 13: “Yes” } & \multicolumn{1}{c}{ Question 13: “No" } \\
\hline & $N$ & $M$ & $S D$ & $N$ & $M$ & $S D$ & $d f$ & $t$ & $p$ & Cohen's $d$ \\
\hline HCCS & 163 & 9.92 & 4.78 & 62 & 5.84 & 3.47 & 151.45 & -7.06 & $0.00^{\star *}$ & 0.98 \\
HCPF & 163 & 12.32 & 5.90 & 62 & 9.67 & 6.26 & 146.70 & -2.90 & $0.00^{\star *}$ & 0.44 \\
HCDS & 163 & 22.2 & 8.99 & 62 & 15.50 & 8.11 & 121.24 & -5.41 & $0.00^{\star *}$ & 0.78 \\
PRDS & 163 & 67.34 & 26.11 & 59 & 49.32 & 18.31 & 154.00 & -5.51 & $0.00^{* *}$ & 0.80 \\
\hline
\end{tabular}

Note. PRDS = Perceived Religious Discrimination Scale, HCDS $=$ Health Care Discrimination Scale/sum of subscales HCCS and HCPF, HCCS = Health Care Cultural Safety Subscale, HCPF = Health Care Patient/ Family Subscale.

${ }^{\star *}$ Correlation is significant at the $p=<.01$.

RQ2. What extent of perceived discrimination do Muslim Americans report?

The total score of the PRDS was used to measure perceived discrimination in society. Higher scores indicated stronger confirmation of exposure to religious discriminatory experiences (Rippy \& Newman, 2008). The mean total score of the PRDS was 61.7, from a possible range of scores of 0 to 132. Relationships between the PRDS and sociodemographic data were analyzed. Comparisons were made between PRDS total scores and gender, place of birth, and use of Muslim clothing using an independent $t$-test. No differences were found between total PRDS scores and gender: females $(M=64.47, S D=25.58)$, males $(M=60.02, S D=24.32), t(187)=1.19, p=.24$. No differences were found between total PRDS scores and whether participants were U.S. born or not: non-U.S. born $(M=60.62, S D=26.24)$, U.S. born $(M=64.67, S D=23.73)$, $t(189)=-1.10, p=.27$. PRDS mean scores for participants who wore Muslim clothing were found to be higher those who did not, and the differences were not significant: Muslim clothing $(67.67, \mathrm{SD}=25.64)$, non-Muslim clothing $(M$ $=54.04, S D=25.64), t(188)=-3.62, p=.00$.

No differences were found between total HCDS scores and gender: females $(M=20.58, S D=9.52)$, males $(M=20.92, S D=9.39), t(187)=.24, p=.81$. No differences were found between total HCDS scores and whether participants 
were U.S. born or not: non-U.S. born $(M=20.76, S D=9.27)$, U.S. born $(M=$ $20.84, \mathrm{SD}=9.55), t(189)=-.05 p=.96$. While HCDS mean scores for participants who wore Muslim clothing were found to be higher those who did not, and the differences were not significant: Muslim clothing $(21.50, \mathrm{SD}=9.32)$, non-Muslim clothing $(M=19.77, S D=9.37), t(188)=-1.23, p=.22$ (see Table $3)$.

TABLE 3. Comparisons Between Total HCDS Score and Gender, Place of Birth, and Use of Muslim Clothing Using Independent $t$-test

\begin{tabular}{lccccccc}
\hline & $N$ & $M$ & $S D$ & $d f$ & $T$ & $p$ & Cohen's $d$ \\
\hline $\begin{array}{l}\text { Gender } \\
\quad \text { Male }\end{array}$ & 74 & 20.92 & 9.39 & 187 & .24 & .81 & .04 \\
$\quad \begin{array}{l}\text { Female } \\
\text { U. Born }\end{array}$ & 115 & 20.58 & 9.52 & & & & \\
$\quad$ No & 106 & 20.76 & 9.27 & 189 & -.05 & .96 & -.01 \\
$\quad$ Yes & 85 & 20.84 & 9.55 & & & & \\
$\quad \begin{array}{l}\text { Muslim Clothing Used } \\
\quad \text { No }\end{array}$ & 71 & 19.77 & 9.37 & 188 & -1.23 & .22 & -.19 \\
$\quad$ Yes & 119 & 21.50 & 9.32 & & & & \\
\hline
\end{tabular}

Note. $\mathrm{HCDS}=$ Health Care Discrimination Scale.

Comparisons were made using Pearson Product Moment Correlations for PRDS total mean score, age, education, and income. The PRDS was negatively correlated with education $(r=-.18, p=.05)$ and positively correlated with age $(r=.20, p=.01$; see Table 4$)$.

TABLE 4. Comparisons Between Total PRDS Score and Age, Education, and Income Using Pearson Product Moment Correlation

\begin{tabular}{lllll}
\hline & PRDS & Age & Education & Income \\
\hline PRDS & & & & \\
Age & .03 & & & \\
Education & $-.18^{\star}$ & $.20^{\star \star}$ & & \\
Income & -.06 & .11 & .07 & \\
\hline
\end{tabular}

Note. PRDS = Perceived Religious Discrimination Scale.

${ }^{*}$ Correlation is significant at the .05 level (2-tailed).

${ }^{\star *}$ Correlation is significant at the .01 level (2-tailed).

RQ3. What extent of perceived discrimination do Muslim Americans report in the U.S. health care setting?

Scores from the two health related subscales, HCCS and HCPF, were summed to calculate HCDS. HCDS scores ranged from 0 to 48 and represent the extent of perceived discrimination in health care settings. Similar to the PRDS, higher 
scores of the HCDS and its subscales indicated stronger perceived discriminatory experiences in health care settings. The two subscales of the HCDS were analyzed to ascertain information about cultural safety within the providerpatient relationship (HCCS), and information about Muslim patient/family cultural care beliefs (HCPF). Possible scores for each of the subscales ranged from 0 to 24. Scores for each of the HCDS subscales were analyzed using mean and standard deviation. The HCCS mean score was lower than that of the $\mathrm{HCPF}$.

To inquire if participants experienced discrimination in the health care setting, item number 13 elicited a "Yes/No" response: Did you ever feel that you were discriminated against in the health care setting because you are Muslim? A total of 62 (27.6\%) responded "Yes" and 163 (72.4\%) responded "No".

RQ4. What are the types of discriminatory behaviors Muslim Americans report in the health care setting in the United States?

A close-ended question was used to answer the fourth research question, which comprised a checklist of six possible answers. Results were reported in frequencies and percentages. Ninety-one (55.4\%) reported being excluded or ignored, $72(43.9 \%)$ reported problems related to wearing Islamic dress, $60(36.6 \%)$ reported offensive or insensitive verbal remarks, $6(3.7 \%)$ reported physical assault, 31 (18.9\%) reported problems related to prayer rituals, and $42(25.6 \%)$ reported problems related to Islamic holidays. An "Other" response was available whereby subjects could add additional types of discrimination. This data was placed into categories created by the researcher and included a total of 32 narrative responses about discrimination. The frequencies and percentages based upon the total number of 30 text entries categories for this item are follows: 4 (13.3\%) clothing, 6 (20\%) harassment/physical threats/verbal abuse, 3 (10\%) diet, 4 (13.3\%) lack of knowledge, 3 (10\%) prayer, 2 (6.7\%) gender issues, 2 (6.7\%) rejection, 2 (6.7\%) stereotypes, and 4 (13.3\%) miscellaneous. The narrative comments, which reveal participant perception of discrimination, are presented in Table 5.

\section{Other Findings}

The two modes of data collection, paper and electronic, were compared. To determine differences between scores of the paper and electronic formats, total scores of each data collection mode were compared using a $t$-test. There was no difference observed between the mean scores of the established PRDS surveys collected electronically $(M=61.69, S D=25.16)$ and the surveys collected by paper format $(M=62.25, S D=33.19), t(-.06)=194, p=.95$. There also was no 
TABLE 5. Other Types of Discrimination Reported by Category

\begin{tabular}{|c|c|c|}
\hline Category & Frequency & Comments \\
\hline Clothing & 4 & $\begin{array}{l}\text { - "Prejudice from a fellow Muslim (non-hijabi) physician after } \\
\text { I described that I would like to seek professional help for } \\
\text { depressive symptoms: rolled eyes, 'typical pre-med, join } \\
\text { the club,' assumed I was overwhelmed by parental pressure } \\
\text { (despite no mention of such on my part). I felt that she pre- } \\
\text { sumed my hijab was done out of passive parentally enforced } \\
\text { religious conformity - that I was backward, silly, and unintel- } \\
\text { ligent. This was my first visit with this clinician.” } \\
\text { - "Because of my hijab I feel I am ignored.” } \\
\text { - "Going into a surgery, health care providers didn't recognize } \\
\text { the importance of me keeping my hijab on and wanting most } \\
\text { of my body covered.” } \\
\text { "They like to leave the door open after the doctor leaves while } \\
\text { I'm not wearing a head scarf or long sleeve shirt. If I'm in a } \\
\text { gown then they close the door.” }\end{array}$ \\
\hline $\begin{array}{l}\text { Harassment } \\
\text { /Physical } \\
\text { Threat/Verbal } \\
\text { Abuse }\end{array}$ & 6 & $\begin{array}{l}\text { - "An attitude that suggests, 'you came to me, so, you'll just } \\
\text { - "Discourage us from getting pregnant. This is extremely of- } \\
\text { fensive. Also they tell us female ob/gyn are not taking new } \\
\text { patients only to find they do the following week. This is very } \\
\text { offensive." } \\
\text { - "Upset behavior." } \\
\text { - Was accused of having abuse in my home when I live } \\
\text { - " "I wone." } \\
\text { - "Berk in the industry and have been harassed." } \\
\text { physical threat messages." }\end{array}$ \\
\hline Diet & 3 & $\begin{array}{l}\text { - "No halal food options except vegetarian." } \\
\text { - "Was served pork for breakfast after overnight hospital stay. } \\
\text { - Apparent oversight." } \\
\text { - "Islamic dietary needs in medication." }\end{array}$ \\
\hline $\begin{array}{l}\text { Lack of } \\
\text { knowledge }\end{array}$ & 4 & $\begin{array}{l}\text { - "Much ignorance in general." } \\
\text { - "They didn't realize that we don't use toilet paper." } \\
\text { - "It's shoot or miss with these guys. Some treat you well and } \\
\text { some don't. The fact that our holy day is Friday was never } \\
\text { taken into consideration even after being explained." } \\
\text { - "I had a doctor say that my headaches were from Christmas } \\
\text { shopping. When I told him I didn't celebrate the holiday } \\
\text { because I'm a Muslim, he then tried to save me!” }\end{array}$ \\
\hline Prayer & 3 & $\begin{array}{l}\text { - "Our son suffered post-natal distress from a nurse abandon- } \\
\text { ing his fetal monitor. I was reading Qur'an to my wife while } \\
\text { - "Nhe was in labor...super display of ignorance." } \\
\text { of the praysarity problems, but rather awkward looks in terms } \\
\text { - "They choose to come right at prayer time to give medicine } \\
\text { or care. If you don't break prayer they don't come back till the } \\
\text { next hour or two." }\end{array}$ \\
\hline
\end{tabular}




\begin{tabular}{|c|c|c|}
\hline Gender Issues & 2 & $\begin{array}{l}\text { - "Requested that the men in the room leave during a colonos- } \\
\text { copy. I was ignored and given anesthesia." } \\
\text { "Bringing in male co-works without my consent. Feeling un- } \\
\text { comfortable with questions asked of me in front of males." }\end{array}$ \\
\hline Rejection & 2 & $\begin{array}{l}\text { - "Problems getting healthcare service in private practices." } \\
\text { "One doctor we went to meet for the first time said "oh" } \\
\text { when she saw us and did not accept us as new patients. } \\
\text { Other times we were treated in an unfriendly way." }\end{array}$ \\
\hline Stereotypes & 2 & $\begin{array}{l}\text { - "Assumed I do not speak English." } \\
\text { - "Victim of ‘guilty by association’ syndrome." }\end{array}$ \\
\hline Miscellaneous & 4 & $\begin{array}{l}\text { - "Not me personally but I do believe a doctor conducted } \\
\text { malpractice which led to my mom's death. She was in an } \\
\text { auto accident; a doctor evaluated her and released her. After } \\
\text { seeing her throw up, I took her to another hospital and they } \\
\text { found she was hemorrhaging in her brain because of the } \\
\text { accident and so they performed immediate surgery. She did } \\
\text { not make it out of the coma. A lawyer settled between us but } \\
\text { my personal belief is that the first doctor had bias in his treat- } \\
\text { ment of my mom. This was in } 1998 \text { in Houston." } \\
\text { - "Sometimes I feel health care providers suck at their job, but } \\
\text { not because I am a Muslim per se. They just have terrible } \\
\text { people skills and aren't very friendly and do not really listen } \\
\text { to or care about their patients." } \\
\text { - "Name pronunciation." } \\
\text {-Felt singled out for very difficult behavior not expected or } \\
\text { observed by/in non-Muslim interactions." }\end{array}$ \\
\hline
\end{tabular}

significant difference noted between the mean scores of the HCDS collected electronically $(M=20.50, S D=9.19)$ and the surveys collected by paper format $(M=18.63, S D=10.54), t(.56)=225, p=.64$.

On April 15, 2013, during the time of data collection, a bombing occurred at the Boston Marathon, in which Muslims from Chechnya were indicted for the resultant three deaths and 264 injured ("April 15 Updates," 2013; Kotz, 2013). Data analysis using a t-test indicated that higher scores of the two instruments used to measure discrimination against Muslims in this investigation were evident after this event. There was a significant difference between PRDS mean score for data collected before the Boston Marathon bombings $(M=59.07, S D=27.75)$ and after and including the date of this incident $(M$ $=67.17, S D=18.85), t(-2.40)=173.05, p=.02$. While the HCDS mean score for data collected before the Boston Marathon bombings $(M=19.61, S D=$ 9.38) and after and including the date of this incident $(M=21.96, S D=8.77)$, $t(-1.85)=225, p=.40$ was higher, the differences were not significant. 


\section{Limitations}

Recruitment strategies using mosques and Muslim organizations limit the sample to those affiliated with such organizations and may exclude secular participants. This research did not capture non-English speakers and those without computers. It excluded Muslim health care employees who also may face discrimination. As this was a first time use of a new tool, the psychometric properties of the HCDS need further study. Not every participant completed all sociodemographic items resulting in incomplete data about this sample. Validity estimates for this instrument would need further testing as construct validity was not undertaken; factor analysis would be required prior to its future use. Though content validity was considered, modifications based upon this feedback would have to be made before continued use of this new tool.

\section{Discussion}

The results of this inquiry suggest that anti-Muslim discrimination crosses over from society to the health care setting in the United States; nearly one-third of subjects perceived they were discriminated against in this setting. Being excluded or ignored was the most frequently conveyed type of discrimination, followed by problems related to the use of Muslim clothing; offensive or insensitive verbal remarks; and problems related to Islamic holidays, prayer rituals, and physical assault, respectively.

Age was positively correlated with perceived anti-Muslim discrimination in society. Education was negatively correlated with perceived discrimination in both society and the health care setting. Three out of five of those surveyed reported that they wear Muslim clothing; the most frequently reported of which was hijab. Females who wear Muslim clothing reported more antiMuslim discrimination than those who did not. Scores for self-reported perceived anti-Muslim discrimination were found to be higher after the Boston Marathon bombings. The most frequent Muslim care preference reported was same-sex caregiver followed by respect for modesty, prayer rituals, respect for privacy, family involvement in care, and dietary concerns. Considerations for culturally congruent care practices for the observant Muslim patient may be addressed with these preferences in mind.

\section{Implications for Practice}

The findings of this study call attention to health care providers to consider the perspectives of Muslim Americans through self-reflection, heightened sensitivity, and culturally congruent care accommodations. It is imperative that 
health care administrators support such efforts in their aim to ensure that optimal care is rendered to not only Muslim Americans, but to all patients.

\section{Self-Reflection}

While many factors contribute to disparities in health, including social, economic, and educational level, there is indication that discriminatory behaviors such as stereotyping and prejudice on the part of health care providers may add to differences in the provision of care (Smedley, Stith, \& Nelson, 2002). In stereotyping, the behaviors of one person or group are considered to be representative of the whole culture and may incite negative feelings if those behaviors are undesirable (Ray, 2010). The presence of stereotyping and discrimination may threaten one's acceptance and respect for cultural beliefs and practices related to health (Maier-Lorenz, 2008).

Ray's (2010) appreciation for Habermas' (as cited in Ray, 2010) explanation that all humans have the propensity to pre-judge; however self-reflection holds value in learning about others. Health care clinicians are as apt to be influenced by the surrounding socio-political context as others. On a professional level, however, they are expected to adhere to professional practice standards in caring for the needs of patients from cultures less familiar than their own. Transcultural caring ethics upholds that providers have a greater obligation above socio-political influences to go beyond the call to care for oneself, to facilitate compassion and caring (Ray, 2010). All health professionals need to reflect on how they and other staff view and relate to Muslim Americans.

\section{Heightened Sensitivity}

The narrative responses about discrimination conveyed by participants reinforced the need for cultural accommodations for Muslims. They also conveyed that some Muslim Americans surveyed faced harassment, physical threats, verbal abuse, stereotypes, and feelings of rejection. Being excluded or ignored was the most frequently conveyed type of discrimination, followed by problems related to the use of Muslim clothing; offensive or insensitive verbal remarks; and problems related to Islamic holidays, prayer rituals, and physical assault, respectively. These perceptions call for heightened sensitivity towards Muslim patients to counter feelings of exclusion and isolation by being intentionally inclusive and cognizant of the presence of Muslim Americans in the clinical setting.

\section{Culturally Congruent Care Accommodations}

Findings from this research upheld those found in other studies regarding accommodations such as same-sex caregiver, prayer rituals, and dietary considerations. This research has added knowledge regarding culturally congruent care 
accommodations in that consideration for privacy and modesty were clearly illuminated as priorities reported by study participants. Overall, the new information gathered in this research was the quantified rank ordered care preferences, which may have varying relevance to Muslim Americans depending on individual preferences. This evidence upholds the diversity among members of this group and should heighten awareness that culturally congruent care accommodations is not a "one size fits" all for Muslim Americans and time must be taken to inquire what matters most to each patient when planning culturally congruent care.

Culturally congruent care is considered beneficial to health outcomes and decreases health costs by improved communication, enhanced patient compliance, decreased emergency room visits, and costly medical services (Schim et al., 2007). This effort intended to quantify care preferences of Muslims, which health care providers may integrate into practice in the interest of providing culturally congruent care. Implications for culturally congruent care responsive to prioritized preferences such as same-sex caregiver, respect for modesty, prayer ritual accommodations, privacy, family involvement, and dietary needs may be addressed in considerate, simplistic ways.

A request for a same-sex caregiver may be accommodated if available. Effective communication and a respectful approach to the patient in this regard may foster trust within the provider-patient relationship. Privacy and modesty may be respected by a simple knock on the door before entering the room of a female patient to give time to place her hijab or scarf properly. This is a courtesy that is likely to be appreciated by any patient, not just Muslims. As findings revealed that both male and female patients who wear Muslim clothing might be at risk for discriminatory behaviors in the health care setting, increased vigilance is needed for patients who wear Islamic dress to be treated with the same respect and equity as other patients.

If a Muslim patient is admitted to a private room, facing the bed east toward Mecca, the direction of prayer, may accommodate prayer rituals. If the patient is ambulatory, they may be oriented to the east by placing a paper indicator on the wall with an arrow in an easterly direction. Family involvement is no different in Muslim families than any other families, which are each unique in character and participation in care. Dietary accommodations that are free from pork and pork products are accommodated easily in most hospitals today.

\section{Role of Health Care Administrators}

In response to changing demographics in the United States, health care professionals must recognize the cultural, linguistic, and informational needs of patients and support quality care "regardless of race, ethnic origin, gender, 
nationality, primary language, socioeconomic status, sexual orientation, cultural background, age, disability, or religion" (American College of Physicians, 2010, p. 1). The impact of immigration on health, health care, and health care policy may result in differences in health care conditions, needs, and services, which create challenges for staff to provide population specific skills (Shrestha \& Heisler, 2013).

To this end, understanding the needs of patients from unfamiliar cultures may be addressed through processes that promote cultural awareness and fair practices, such as continuing education, orientation programs, and policies. Moreover, successful surveys conducted by the Joint Commission increasingly require compliance to regulatory standards that mandate language accommodations, "effective communication, cultural competence, and patient- and family-centered care from the same perspective" (Joint Commission, 2010, p. 1). Administrators who seek to learn about the preferences of Muslim patients may improve patient satisfaction survey scores. Additionally, health care leaders who are aware of possible predictors of discrimination are empowered to reduce risk for litigation related to discriminatory behavior.

As pastoral care is present in most in-patient institutions for some religions, the inclusion of Muslim religious leaders may benefit the staff and patients. Administrators may partner with these individuals to provide education to staff about Islamic religious beliefs, which serves to bridge the knowledge gap about this faith as well as to offer spiritual support to patients.

\section{Implications for Education}

Discrimination results, in part, from lack of knowledge about a social group and prejudice about its faith, tenets, and values (Thornicroft, Mehta, Brohan, \& Kassam, 2010). A lack of knowledge about Islam persists in the United States; a national study has revealed that over half of Americans say they know little or nothing about Islam (Pew Forum on Religious and Public Life, 2010). One intention of this inquiry was to uncover insensitive behavior in health care settings and inadequacy in meeting patient/family cultural needs. Nearly onethird of Muslim subjects perceived to be discriminated in the health care setting. It is unknown whether perceived discrimination was related to lack of knowledge on the part of the caregivers or other reasons. Nonetheless, this finding suggests that all health professionals need to assess what they know and do not know about Islam.

Implications for education entail nursing, medical, and other health care provider initial academic preparation and ongoing continuing education for staff. Health care provider faculty and clinical educators can use these findings 
to enhance transcultural knowledge into initial and continuing education that prepares staff for practice in culturally diverse settings, capable of providing culturally congruent care for Muslim patients.

The findings for this study may be used in all educational venues for providers to gain insights to the profile of Muslim Americans based upon empirical data. This study uncovered that some Muslims perceive a lack of knowledge about Islam both in society and in the health care setting. Sociodemographic descriptions about this group as educated, affluent, religiously observant, and largely non-U.S. born, provide opportunity to understand the commonalities among this group. The fact that many Muslims are U.S. born, do not wear Muslim clothing, and do not practice prayer rituals conveys the diversity among individuals in this group.

The evidence that discrimination exists not only in society, but also in health care, should alert educators to problems Muslim Americans may have in the health care setting such as females who wear Muslim clothing who feel ignored, breaches of respect for modesty and privacy, and incorrect diet provisions. The evidence of physical assault should alert providers to extremes that may occur. Staff may be educated about specific care accommodations that were quantified in this research in order to enhance understanding of the needs of these patients.

Health care faculty and clinical educators may access the Transcultural Nursing Society (TCNS), founded by Madeline Leininger in 1974, as an excellent resource for the domain of transcultural knowledge. Membership is available to the society, whose mission is to improve the quality of culturally congruent and competent care that aims for improved health for all persons. The goals of the TCNS are to advance cultural competence worldwide and to develop strategies for advocating social change for culturally competent care (TCNS, 2013). This society is a rich resource for continuing education as it offers professional publications, educational activities, cultural advocacy, and international networking. Nurses may obtain Certification in transcultural nursing at the basic and advanced levels through established application and examination processes.

Clinical educators are key resources to ensure knowledge and compliance of regulatory standards and professional guidelines that support the provision of culturally congruent care practices, such as the Joint Commission. Staff benefit from guidance provided by clinical educators who are knowledgeable about transcultural practice. Educational updates about the demographics of populations served in organizations and their specific cultural preferences related to health care may enhance the quality of care and improve patient satisfaction. 


\section{Implications for Policy}

All practitioners must be vigilant in upholding patient, civil and human rights in practice. The Civil Rights Acts of 1964 legally protects Americans against discrimination of all types, including racial, ethnic, and religious. Clinical staff must act as patient advocates and uphold fair and equitable treatment of patients and report civil right violations in the clinical setting with diligence. The U.S. census, conducted every 10 years, gathers data related to immigration, race, and ethnicity, (U.S. Census Bureau, 2013), but does not track religion.

\section{Considerations for Further Research}

Further testing of the reliability and validity of the newly created HCDS includes the need for revision of items based on content validity information provided by researchers with expertise on the Muslim population and a factor analysis. The HCDS could be adapted for use among other groups in order to ascertain the possibility of discriminatory encounters and care preferences among other groups in the health care setting. The PRDS, originally employed among Arab American civilians, also may be modified by eliminating verbiage about this ethnic group so it has a more general focus to all Muslim Americans. Additionally, factor analysis may be beneficial to reduce the length of this 33item tool. The addition of an item to elicit geographic data, such as zip codes, may provide insight to locations where anti-Muslim discrimination is more or less pronounced.

As electronic and paper formats of the survey were employed, it is recommended that this approach be considered as a means to include participants who do not have access to computers, thus diversifying the sample. However, face-to-face completion of a survey about anti-Muslim discrimination may be challenging due to the sensitive nature of the subject. After the Boston Marathon bombings, this researcher was informed by a group of Islamic school teachers who had agreed to compete papers surveys, that they would not proceed due to fear of reprisal in light of the social tensions after this crime in which Muslims were indicted. The continuation of computer-based research might be beneficial to support anonymity and privacy for subjects. Recruitment of patients upon discharge from health care settings with snowball sampling is another means to diversify the sample by capturing individuals who do not necessarily belong to Muslim organizations.

During the course of this work, an array of language used in studies about discrimination was observed. For example, some authors solely used the term "discrimination" and others used the term "religious discrimination." Distinctions between racial, ethnic, and religious discrimination often are unclear 
(Sheridan, 2006), which compels researchers to clarify focus, purpose, and outcomes so as to move in new directions for religion-related discrimination.

As the U.S. census does not track religion, it is necessary for researchers to find credible sources of information to support studies specifically about religious discrimination per se. Additionally, as the diversity of the United States continues, so too may the need be for investigations about discrimination in health care against other religious minorities in this country be enhanced.

Quantified data about the extent and types of anti-Muslim discrimination may suggest predictors of discrimination by clarifying factors that place Muslims at-risk for suboptimal well being and barriers to opportunity, such as being ignored and excluded, problems related to the use of Muslim clothing, offensive remarks, problems related to Muslim holidays and prayer rituals, and even physical assault.

The presence of research conducted outside the United States on antiMuslim discrimination shows that this is a problem beyond the borders of this country. International multidisciplinary awareness of anti-Muslim discrimination may improve the circumstances of Muslims in other countries. The results of this study add to the research literature about the extent and types of antiMuslim discrimination in health care. Future research will focus on refinement of the HCDS and studies to ascertain whether educational programs make a difference in reducing this problem.

\section{Conclusion}

Interest for this study stemmed from concerns about one religious minority in the United States. As this nation continues to be an international destination for opportunity and freedom from oppression, war, and political strife, it is anticipated that immigrants will continue to arrive in the pursuit of a better life. The complexities of socio-political circumstances faced by Muslim Americans and the health care dynamics therein may be duly applied to other groups of immigrants and minorities; health care providers must uphold patient, civil, and human rights in practice and be aware of consequences of their violation. Through what has been learned in this inquest, it is hoped that culturally astute staff guide the interdisciplinary team to enact inclusion to overcome the confines of geography, language, traditions, religion, ethnicity, and culture with the intention to embrace a "common humanity" (Ray, 2010, p. 95). In doing so, the opportunities for personal and professional growth in the provision of culturally congruent care for the Muslim patient will far surpass the challenges faced along this journey, to benefit humankind, one patient at a time. 


\section{References}

Abu-Ras, W., \& Abu-Bader, S. (2009). Risk factors for depression and posttraumatic stress disorder (PTSD): The case of Arab and Muslim Americans post-9/11. Journal of Immigration and Refugee Studies, 7, 393-418. doi: 10.1080/15562940903379068

Abu-Ras, W., \& Laird, L. (2011). How Muslim and non-Muslim chaplains serve Muslim patients? Does the interfaith chaplaincy model have room for Muslims' experiences? Journal of Religious Health, 50, 46-61. doi: 10.1007/s10943-010-9357-4

Ahmed, S., \& Reddy, L. (2007). Understanding the mental health needs of American Muslims: Recommendations and considerations for practice. Journal of Multicultural Counseling and Development, 35, 207-218. Retrieved from onlinelibrary.wiley.com. DOI: http://dx.doi.org/10.1002/j.2161-1912.2007.tb00061.x

Ameena, A., Mohammed, S., \& Williams, D. (2007). Racial discrimination and health: Pathways and evidence. Indian Journal of Medical Research, 126, 318-327. Retrieved from www.ncbi.nlm.nih.gov/pubmed/18032807

Amer, M., \& Hovey, J. (2007). Sociodemographic differences in acculturation and mental health for a sample of 2nd generation/early immigrant Arab Americans. Journal of Immigrant and Minority Health, 9, 335-347. doi: 10.1007/s10903-9045-y

Amer, M., \& Hovey, J. (2012). Anxiety and depression in a post-September 11 sample of Arabs in the USA. Social Psychiatry and Psychiatric Epidemiology, 47, 409-418. doi: 10.1007/s00127-011-0341-4

American College of Physicians. (2010). Racial and ethnic disparities in health care, updated 2010. Philadelphia: American College of Physicians.

April 15 updates on explosions at the Boston Marathon. (2013, April 15). The New York Times. Retrieved from http://thelede.blogs.nytimes.com/2013/04/15/live-updatesexplosion-at-boston-marathon/?_r=0

Arab American Institute. (2015). American attitudes towards Arabs and Muslims. Retrieved from

http://www.aaiusa.org/american-attitudes-toward-arabs-and-muslims-2014

Aroian, K. (2012). Discrimination against Muslim American adolescents. The Journal of School Nursing, 28(3), 206-213. doi: 10.1177/1059840511432316

Athar, S. (1996). Islamic perspectives in medical ethics. In S. Athar (Ed.), Islamic perspectives in medicine: A survey of Islamic medicine: Achievements \& contemporary issues (pp. 187-194). Chicago, IL: Kazi Publications.

Bagby, I. (2011). The American Mosque: Report One. Retrieved from http://faithcommunitiestoday.org/sites/faithcommunitiestoday.org/files/The\%20American\%20 Mosque\%202011\%20web.pdf

Bagby, I., Perl, P. M., \& Froehle, B. T. (2001). The mosque in America: A national portrait. Washington, DC: Council on American Islamic Relations.

Barkdull, C., Khaja, K., Queiro-Tajalli, I., Swart, A., Cunningham, D., \& Dennis, S. (2011). Experiences of Muslims in four Western countries post-9/11. Affilia, Journal of Women and Social Work, 26(2), 139-153. doi: 10.1177/0886109911405491

Betancourt, J., Green, A. Carrillo, J., \& Anenah-Firempong, O. (2003). Defining cultural competence: A practical framework for addressing racial/ethnic disparities in health and health care. Public Health Reports, 118, 293-302. Retrieved from ncbi.nlm.nih.gov/pubmed/12815076. DOI: http://dx.doi.org/10.1016/S00333549(04)50253-4

Carlsson, M., \& Rooth, D. (2007). Evidence of ethnic discrimination in the Swed- 
ish labor market using experimental data. Labour Economics 14, 716-729. doi: 10.1016/j.labeco.2007.05.001

Charles, C., \& Daroszewski, E. (2012). Culturally competent nursing care of the Muslim patient. Issues in Mental Health Nursing, 33(1), 61-63. doi: $10.3109 / 01612840.2011 .596613$

Civil Rights Act of 1964. (n.d.). Retrieved from the Office of the Clerk, U.S. House of Representatives website: http://library.clerk.house.gov/reference-files/PPL_Civil RightsAct_1964.pdf

De Chesnay, M., \& Anderson, B. A. (2008). Caring for the vulnerable: Perspectives in nursing theory, practice and research. Boston, MA: Jones and Bartlett.

Department of Health and Human Services. (2011). HHS action plan to reduce racial and ethnic health disparities. Retrieved from http://minorityhealth.hhs.gov/npa/ files/Plans/HHS/HHS_Plan_complete.pdf

Erickson, C., \& Al-Tamimi, N. (2001). Providing mental health services to Arab Americans: Recommendations and considerations. Cultural Diversity in Ethnic Minority Psychology, 7(4), 308-327. doi: 10.1037/1099-9809.7.4.308

Fozdar, F. (2012). Social cohesion and skilled Muslim refugees in Australia: Employment, social capital, and discrimination. Journal of Sociology 48, 167-186. doi: $10.1177 / 1440783311413482$

Ghaffari, A., \& Çiftçi, A. (2012). Religiosity and self-esteem of Muslim immigrants to the United States: The moderating role of perceived discrimination. The International Journal for the Psychology of Religion, 20, 14-25. doi: 10.1080/10508610903418038

Ghumman, S., \& Jackson, L. (2010). The downside of religious attire: The Muslim headscarf and expectations of obtaining employment. Journal of Organizational Behavior, 31, 4-23. doi: 10.1002/job.601

Ghumman, S., \& Ryan, A. (2013). Not welcome here: Discrimination towards women who wear the Muslim headscarf. Human Relations, 66, 671-698. doi: $10.1177 / 0018726712469540$

Hassouneh, D., \& Kulwicki, A. (2007). Mental health, discrimination, and trauma in Arab women living in the US: A pilot study. Mental Health, Religion \& Culture, 10(3), 257-262. doi: 10.1080/13694670600630556

Huda, Q. (2006). The diversity of Muslims in the United States: Views as Americans. Retrieved from United States Institute of Peace website: http://www.usip.org/publications/diversity-muslims-united-states-views-americans

Institute of Medicine. (2012). How far have we come in reducing health disparities?: Progress since 2000: Workshop summary. Washington, DC: The National Academies Press.

Iqbal, M. (2007). Science and Islam. Westport, CT: Greenwood Press.

Jasperse, M., Ward, C., \& Jose, P. (2012). Identity, perceived religious discrimination, and psychological well-being in Muslim immigrant women. Applied Psychology: An International Review, 61(2), 250-271. doi: 10.1111/j.1464-0597.2011.00467.x

Johnston, D., \& Lordon, G. (2011). Discrimination makes me sick! An examination of the discrimination-health relationship. Journal of Health Economics, 31, 99-111. doi: 10.1016/j.jhealeco.2011.12.002

The Joint Commission. (2010). Advancing effective communication, cultural competence, and patient and family centered care: A roadmap for hospitals. Retrieved from http://www.jointcommission.org/assets/1/6/aroadmapforhospitalsfinalversion727.pdf 
King, E., \& Ahmad, A. (2010). An experimental field study of interpersonal discrimination towards Muslim job applicants. Personnel Psychology, 63, 881-906. Retrieved from onlinelibrary.wiley.com. DOI: http://dx.doi.org/10.1111/j.17446570.2010.01199.x

Kira, I., Lewandowski, L., Templin, T., Ramaswamy, V., Ozkan, B., \& Mohanesh, J. (2010). The effects of perceived discrimination and backlash on Iraqi refugees' mental and physical health. Journal of Muslim Mental Health, 5, 59-81. doi: $10.1080 / 15564901003622110$

Koenig, H. (2005). Religion, spirituality and medicine: The beginning of a new era. Southern Medical Journal, 98, 1235-1236. Retrieved from www.ncbi.nlm.nih.gov/ pubmed/16440934. DOI: http://dx.doi.org/10.1097/01.smj.0000190305.48575.ab

Kotz, D. (2013, April 24). Injury toll from Marathon bombs reduced to 264. The Boston Globe. Retrieved from http://www.bostonglobe.com/lifestyle/healthwellness/2013/04/23/number-injured-marathon-bombing-revised-downward/ NRpaz5mmvGquP7KMA6XsIK/story.html

Kulwicki, A., Khalifa, R., \& Moore, G. (2008). The effects of September 11 on Arab American nurses in metropolitan Detroit. Journal of Transcultural Nursing, 19, 134-139. doi: 10.1177/1043659607313071

Kyriakides-Yeldham, A. (2005). Islamic medical ethics and the straight path of God. Islam and Christian-Muslim Relations, 16(3), 213-225. Retrieved from www.tandfonline.com.

Laird, L., Amer, M., Barnett, E., \& Barnes, L. (2007). Muslim patients and health disparities in the U.K and the U.S. Archives of Diseases in Childhood, 92, 922-926. Retrieved from www.ncbi.nlm.nih.gov/pubmed/17895342. DOI: http://dx.doi. org/10.1136/adc.2006.104364

Martin, M. (2012). Perceived religious discrimination and its relationship to satisfaction with nursing care among Muslims in the United States. Unpublished doctoral pilot study, the Christine E. Lynn College of Nursing, Florida Atlantic University, Boca Raton, FL.

Martin, S. (2012). Exploring discrimination in American health care system: Perceptions/experiences of older Iranian immigrants. Journal of Cross Cultural Gerontology, 27, 291-304. doi: 10.1007/s10823-012-9168-z

McNulty, D. (2008). The adequacy of response rates to online and paper surveys: What can be done? Assessment \& Evaluation in Higher Education, 33(3), 301-314. doi: $10.1080 / 02602930701293231$

Maier-Lorenz, M. (2008). Transcultural nursing: Its importance in nursing practice. Journal of Cultural Diversity, 15(1), 37-43. Retrieved from www.ncbi.nlm.nih.gov/ pubmed/19172978

Moradi, B., \& Hasan, N. (2004). Arab American persons' reported experiences of discrimination and mental health: The mediating role of personal control. Journal of Counseling Psychology, 51, 418-442. doi: 10.1037/0022-0167.51.4.418

Muscati, S. (2002). Arab/Muslim 'Otherness': The role of racial constructions in the Gulf War and the continuing crisis with Iraq. Journal of Muslim Minority Affairs, 22(1), 131-148. doi: 10.1080/13602000220124872

Narayanasamy, A. (2003). Transcultural nursing: How do nurses respond to cultural needs? British Journal of Nursing, 12(3), 185-194. Retrieved from http://www.ncbi. nlm.nih.gov/pubmed/12610374.

Nasr, S. (2003). Islam: Religion, history, and civilization. New York: Harper Collins. 
National Commission on Terrorist Attacks. (2004). The 9/11 Commission report: Final report of the National Commission on Terrorist Attacks upon the United States. New York: W.W. Norton.

National Institutes of Health (2010). NIH health disparities strategic plan and budget fiscal years 2009-2013. Washington, DC: Department of Health and Human Services.

Nigosian, S. (2004). Islam: Its history, teaching, and practices. Bloomington, IN: Indiana University Press.

Padela, A., Gunter, K., Killawi, A., \& Heisler, M., (2012). Religious values and healthcare accommodations: Voices from the American Muslim community. Journal of General Internal Medicine, 27, 708-715. doi: 10.1007/s11606-011-1965-5

Padela, A., \& Heisler, M. (2010) The association of perceived abuse and discrimination after September 11, 2001, with psychological distress, level of happiness, and health status among Arab Americans. American Journal of Public Health, 100(2), 284-291. doi: 10.2105/AJPH.2009.164954

Peek, L. (2011). Behind the backlash: Muslim Americans after 9/11. Philadelphia, PA: Temple University Press.

Pew Forum on Religious and Public Life. (2008). U.S. religious landscape survey. Retrieved from http://www.umsl.edu/ keelr/010/Pew_Report_on_Religion

/report-religious-landscape-study-full.pdf

Pew Forum on Religious and Public Life. (2009). Views of religious similarities and differences: Muslims widely seen as facing discrimination. Retrieved from http://www. pewforum.org/uploadedfiles/Topics/Religious_Affiliation/Muslim/survey0909. pdf

Pew Forum on Religious and Public Life. (2010). Public remains conflicted over Islam. Retrieved from

http://www.pewforum.org/2010/08/24/public-remains-conflicted-over-islam/

Pew Research Center Religious and Public Life. (2011). Table: Muslim population by country. Retrieved from http://www.pewforum.org/2011/01/27/table-muslim-population-by-country/

Ramsden, I., \& Papps, E. (1996). Cultural safety in nursing: The New Zealand experience. International Journal for Quality in Healthcare, 8(5), 491-497. Retrieved from intqhc.oxfordjournals.org/content/8/5/491.short. DOI: http://dx.doi.org/10.1093/ intqhe/8.5.491

Rassoul, G. (2000). The crescent and Islam: Healing, nursing and the spiritual dimension. Some considerations towards an understanding of the Islamic perspectives on caring. Journal of Advanced Nursing, 32, 1476-1484. Retrieved from www. ncbi.nlm.nih.gov/pubmed/11136416. DOI: http://dx.doi.org/10.1046/j.13652648.2000.01614.x

Ray, M. (2010). Transcultural caring dynamics in nursing and health care. Philadelphia, PA: F.A. Davis.

Read, J. (2008). Muslims in America. Contexts, 7, 39-43. doi: 10.1525/ctx.2008.7.4.39

Riaz, M. N., \& Chaudry, M. M. (2003). Halal food production. Boca Raton, FL: CRC Press. http://dx.doi.org/10.1201/9780203490082

Rippy, A., \& Newman, E. (2008). Adaptation of a scale of race-related stress for use with Muslim Americans. Journal of Muslim Mental Health, 3, 53-68. doi: $10.1080 / 15564900802035292$

Scott, G., \& Franzmann, M. (2007). Religious identity and 'secular' employment: A case study of young Muslim women graduates in the Sydney workforce. Contemporary Islam, 1, 275-288. doi: 10.1007/s11562-007-0026-7 
Shammas, D. (2009). Post 9/11 Arab and Muslim American community college students: Ethno-religious enclaves and perceived discrimination. Community College Journal of Research and Practice, 33, 283-308. doi: 10.1080/10668920802580507

Sheridan, L. (2006). Islamophobia pre-and post-September $11^{\text {th }}, 2001$. Journal of Interpersonal Violence, 21(3), 317-336. doi: 10.1177/0886260505282885

Shrestha, L., \& Heisler, E. (2013). The changing demographic profile of the United States. Retrieved from Congressional Research Service website: http://www.fas.org/sgp/ crs/misc/RL32701.pdf

Smedley, B., Stith, A., \& Nelson, A. (2002). Unequal treatment: Confronting racial and ethnic disparities in health care. Washington, DC: National Academy Press. Retrieved from http://www.iom.edu/ /media/Files/Report

Sundquist, E. (1988). The Japanese-American internment: A reappraisal. The American Scholar, 57(4), 529-547. Retrieved from www.jstor.org/stable/41211623

Thornicroft, G., Mehta, N., Brohan, E., \& Kassam, A. (2010). Stigma and discrimination. In C. Morgan and D. Bhugra. Principles of social psychiatry. Chichester, UK: John Wiley \& Sons, Ltd. http://dx.doi.org/10.1002/9780470684214.ch26

United States Census Bureau. (2013). U.S.A. quick facts. Retrieved from

http://quickfacts.census.gov/qfd/states/00000.html

United States Department of State. (2009). Being Muslim in America. Washington D.C.: Bureau of International Information on Programs. Retrieved from http://www.america.gov/publications/books/being-muslim-in-america.html

U.S. Government Printing Office. (2001).The PATRIOT Act. Retrieved from http://www.gpo.gov/fdsys/pkg/PLAW-107publ56/pdf/PLAW-107publ56.pdf

Wehbe-Alamah, H. (2008). Bridging generic and professional care practices for Muslim patients through use of Leininger's culture care modes. Contemporary Nurse, 28(1-2), 83-97. doi: 10.5172/conu.673.28.1-2.83

Westra, A., Willems, D., \& Smit, B. (2009). Communicating with Muslim parents: “The four principles" are not as culturally neutral as suggested. European Journal of Pediatrics, 168, 1383-1387. doi: 10.1007/s00431-009-0970-8

Widner, D., \& Chicoine, S. (2011). It's all in the name: Employment discrimination against Arab Americans. Sociological Forum, 26, 806-823. doi: 10.1111/j.1573-7861.2011.01285.x

Williams, D., Neighbors, H., \& Jackson, J. (2003). Racial/ethnic discrimination and health: Findings from community studies. American Journal of Public Health, 93(2), 200-208. doi: 10.2105/AJPH.93.2.200 